\title{
A Case of Delayed Cardiac Tamponade: Highlighting the Importance of Transthoracic Echocardiography Training for Anesthesiologists
}

Kelly T Peretich, Jeffrey C Liu, Samir Saba, Heather Byrd, Kathirvel Subramaniam

\begin{abstract}
This echo report describes a patient who developed cardiac temponade in the post-anesthesia care unit after laser lead extraction at electrophysiology laboratory. Diagnosis was readily established by transthoracic echocardiography and this lead to good outcome. Transthoracic ultrasound helps in preoperative evaluation of non-cardiac surgical patients and also postoperative care of hemodynamically unstable patients. This describes the importance of training and competence in transthoracic ultrasound for anesthesiologists.
\end{abstract}

Keywords: Transthoracic ultrasound, Cardiac tamponade, Laser lead extraction.

How to cite this article: Peretich KT, Liu JC, Saba S, Byrd $\mathrm{H}$, Subramaniam K. A Case of Delayed Cardiac Tamponade: Highlighting the Importance of Transthoracic Echocardiography Training for Anesthesiologists. J Perioper Echocardiogr 2013; 1(2):69-71.

\section{Source of support: Nil}

Conflict of interest: None declared

\section{CASE REPORT}

A 55-year-old man with a past medical history significant for nonischemic cardiomyopathy with a left ventricular ejection fraction of $20 \%$, type II diabetes mellitus, obesity, hypertension, and hyperlipidemia presented for battery change and lead replacement of an automatic implantable cardioverter defibrillator (AICD) that had been placed 6 years earlier. During the procedure performed under general anesthesia, the patient developed brief period of hypotension requiring an epinephrine infusion. Otherwise the procedure was uneventful. After completion of the procedure, the epinephrine infusion was discontinued, patient was extubated and brought to the postanesthesia care unit (PACU) for recovery. Patient was awake, alert, and oriented upon arrival to the PACU and blood pressure was 94/59 $\mathrm{mmHg}$ with a heart rate of $80 / \mathrm{min}$. Mean blood pressure remained in the low normal range $(60-70 \mathrm{~mm} \mathrm{Hg})$, but the patient repeatedly stated that he felt well. Approximately, 2 hours after the procedure, the patient began to complain of chest pain, and his blood pressure dropped further to $72 / 44 \mathrm{~mm} \mathrm{Hg}$. On physical examination, the patient appeared pale, his lungs were clear, and no murmurs were appreciated. A 12-lead EKG showed no changes from his preoperative study. A bedside transthoracic echocardiogram (TTE) was requested by the anesthesia team. Cardiologist immediately reached PACU and performed TTE examination, which showed a sizeable pericardial effusion with evidence of tamponade physiology, and he was taken emergently for evacuation in the catheterization laboratory. Two hundred fifty milliliters of blood were removed. Patient was monitored in the cardiac care unit overnight without signs of reaccumulation of fluid before being discharged home.

\section{DISCUSSION}

There are approximately 180,000 permanent pacemakers and 70,000 AICDs implanted in the United States each year, and the frequency is steadily increasing. ${ }^{1,2}$ As the number of devices increases so does the need for lead extraction, which is indicated in cases of infection, lead failure, device recall and lead or lead fragment causing life-threatening arrhythmias, embolic events, vessel obstruction, or interference with the operation of another implanted device. ${ }^{3}$ Often, lead extraction can be done with direct traction, however, the longer the time from implantation the greater the likelihood of formation of fibrotic sheaths at the tip as well as along the length of the lead itself that risk injury to tissues when traction is applied. In these cases, using a laser is one of the more frequently used methods to free the lead from these adhesions and extract it . ${ }^{4}$ Pericardial effusion is a known complication of lead extraction, and the Heart Rhythm Society (HRS) issued a policy statement that defines pericardial effusion requiring intervention as a major complication of this procedure (Fig. 1 and Video 1). ${ }^{3}$ Reported rates of major complications during laser lead extraction range from 0.4 to $3.4 \% .^{4-6}$

For over two decades, and especially in the setting of cardiac surgery, transesophageal echocardiography (TEE) has been a well-recognized intraoperative tool for the cardiac anesthesiologist. In a hemodynamically unstable patient, echocardiography can quickly provide information on the anesthetized patient's circulatory status including insight into etiology as well as the adequacy of response to intervention. However, the anesthesiologist's care of patients includes assessment prior to their scheduled procedure and management of their care in the postoperative setting as well. Many have begun to make the argument for transthoracic echocardiography (TTE) as an important adjunct in the anesthesiologist's evaluation and management of surgical patients. ${ }^{7,8}$ As more emphasis is placed on the 


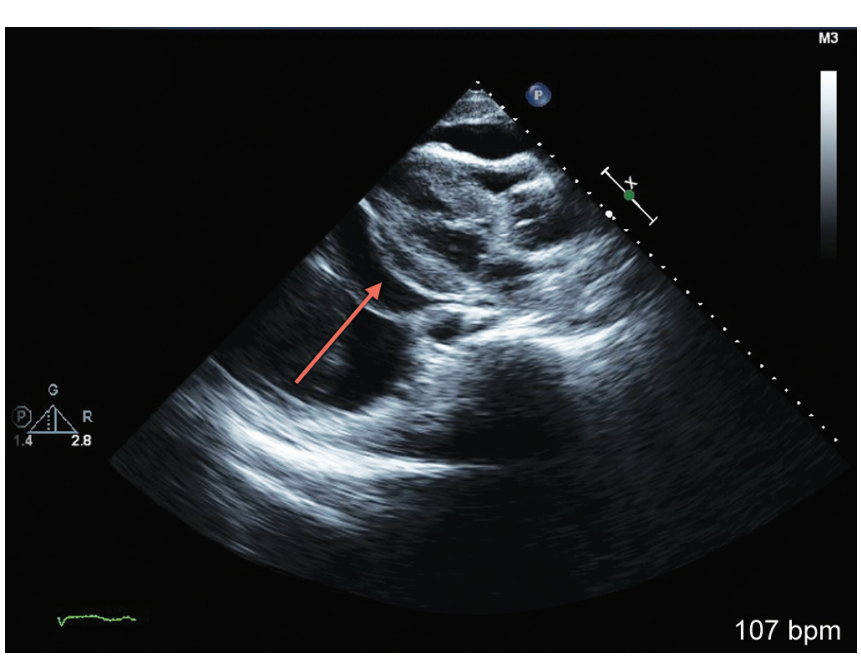

Fig. 1: Pericardial-effusion (arrow) causing diastolic RV collapse

anesthesiologist as a perioperative physician, the lessinvasive TTE may become more of a valued tool to help to guide and improve overall patient care.

As evidenced by the case above, TTE can provide valuable information in the hemodynamically unstable patient that can help to guide management, similar to TEE, with the added benefit of not requiring an esophageal probe. This is ideal in the awake and alert patient in the recovery room. Use of TTE often allows the clinician to gain insight into a patient's condition beyond what is possible with standard clinical evaluation..$^{9}$ In the immediate postoperative period, complications can present and progress quickly so their efficient early diagnosis and treatment is a key responsibility of the anesthesiologist. Postoperative complications including pericardial effusion, impaired contractility, and volume overload/depletion all have the potential to lead to hemodynamic decompensation and can be diagnosed at the bedside with a focused TTE examination. ${ }^{10-13}$ In hypotensive patients, Joseph et al found TTE to have a positive predictive value of $97 \%$ and a negative predictive value of $100 \%$ in the identification of patients with cardiogenic shock. ${ }^{14}$

There is increasingly more evidence for the utility of the focused TTE as a preoperative evaluation tool as well. Focused TTE offers a quick and noninvasive way to gather information on a patient's cardiac function and so has changed the management of both patients being evaluated in the preoperative clinic setting as well as presenting for more emergent procedures. In studies of anesthesiologistperformed preoperative TTE's in the clinic setting, changes in perioperative management occurred in 54 to $82 \%$ of patients. ${ }^{15-18}$ The TTE has the potential to be invaluable in the emergency setting as well when the patient may not be able to provide an adequate history and/or there is no time for more in-depth evaluations of cardiac function. In addition to affecting perioperative management, anesthesiologist- performed perioperative TTE has been shown to predict adverse cardiac events following noncardiac surgery. ${ }^{19}$

The advantages of the focused TTE extend beyond the information it provides. TTE is noninvasive and focused examinations can be performed rapidly at bedside in 10 to $15 \%$ of the time it would take for a formal TTE. ${ }^{20}$ One study approximates that 10 minutes are sufficient for a focused TTE examination. ${ }^{9}$ However, the FATE (focus assessed transthoracic echocardiography) examination's five steps that include looking for obvious pathology, assessing wall thickness and chamber dimensions, assessing biventricular function, visualizing pleura, and relating information to the clinical context are touted to be able to be completed in as little as 70 seconds. ${ }^{21}$ The rapidity with which the study can be performed adds to its value in the acute setting.

Of course, having a TTE available is of very little, if any, aid to the anesthesiologist without the knowledge and training on how to perform and interpret the study, and arguments are beginning to be made for the implementation of TTE skills in anesthesia training programs. ${ }^{21,22}$ Training is paramount to the quality of focused TTE examinations, but even brief training has been shown to be of use in the clinical setting. ${ }^{9,21,23-26}$ Noncardiologist critical care residents were able to use point-of-care ultrasound to address simple clinical questions after only a 3-hour training course and 5 hours of supervised hands-on training. ${ }^{21}$ Surgical intensivists were also shown to perform and interpret focused TTE examinations correctly $84 \%$ of the time after 11 -hour courses. ${ }^{9}$ Vignon et al suggest that a 12 -hour training course with a mixture of didactics and hands-on experience is sufficient for noncardiology residents to achieve competency in basic critical care echocardiography. ${ }^{25}$ Furthermore, Cowie showed that anesthesiologists were able to obtain quality images in $98 \%$ of cases and their findings correlated with formal cardiologist performed TTE's in $87 \%$ of cases. ${ }^{16}$ The implementation of point-of-care ultrasound to make clinical decisions in settings, such as emergency medicine and critical care offers further evidence that such a training program is feasible for the anesthesiologist as well. ${ }^{22,24,25,27}$

\section{SUMMARY}

Transthoracic echocardiography is a useful tool for the anesthesiologist's perioperative management of surgical patients. It is made even more useful by the fact that it is noninvasive, rapid to perform and is feasible to both learn and apply.

\section{REFERENCES}

1. Greenspon AJ, Patel JD, Lau E, Ochoa JA, Frisch DR, Ho RT, Pavri BB, Kurtz SM. Trends in permanent pacemaker implantation in the United States from 1993 to 2009: increasing 
complexity of patients and procedures. J Am Coll Cardiol 2012;60(16):1540-1545.

2. Zhan C, Baine WB, Sedrakyan A, Steiner C. Cardiac device implantation in the United States from 1997 through 2004: a population-based analysis. J Gen Intern Med 2008;1:13-19.

3. Wilkoff BL, Love CJ, Byrd CL, Bongiorni MG, Carrillo RG, Crossley GH 3rd, Epstein LM, Friedman RA, Kennergren CE, Mitkowsky P, et al. Transvenous lead extraction: Heart Rhythm Society Expert consensus on facilities, training, indications and patient management. Heart Rhythm 2009;6(7):1085-1104.

4. Farooqi FM, Talsania S, Hamid S, Rinaldi CA. Extraction of cardiac rhythm devices: indications, techniques and outcomes for the removal of pacemaker and defibrillator leads. Int J Clin Pract 2010;64(8):1140-1147.

5. Garmon EH, Johnston WE. Complications with laser-lead extraction. J Cardiothorac Vasc Anesth 2010;24(6):974-976.

6. Bongiorni MG, Soldati E, De Lucia R, Marzilli M. Minerva cardioangiol: Techniques for transvenous leads extraction. Minerva Cardioangiol 2007;55(6):771-781.

7. Shillcutt SK, Markin NW, Montzingo CR, Brakke TR. Use of rapid 'rescue' perioperative echocardiography to improve outcomes after hemodynamic instability in noncardiac surgical patients. Cardiothorac Vasc Anesth 2012;26(3):362-370.

8. Yeates TM, Zimmerman JM, Cahalan MK. Perioperative echocardiography: two-dimensional and three-dimensional applications. Anesthesiol Clin 2008;26(3):419-435.

9. Manasia AR, Nagaraj, HM, Kodali RB. Feasibility and potential clinical utility of goal-directed transthoracic echocardiography performed by noncardiologist intensivists using a small hand carried device (SonoHeart) in critically ill patients. J Cardiothorac Vasc Anesth 2005;19:155-159.

10. Pepi M, Muratori M. Echocardiography in the diagnosis and management of pericardial disease. J Cardiovas Med 2006;7(7):533-544.

11. Tanzola RC, Walsh S, Hopman WM, Sydor D, Arellano R, Allard RV. Brief report: focused transthoracic echocardiography training in a cohort of Canadian anesthesiology residents: a pilot study. Can J Anaesth 2013;60(1):32-37.

12. Saranteas T, Alevizou A, Tzoufi M, Panou F, Kostopanagiotou G. Transthoracic echocardiography for the diagnosis of left ventricular thrombosis in the postoperative care unit. Crit Care 2011;15(1):R54.

13. Noritomi DT, Vieira ML, Mohovic T, Bastos JF, Cordioli RL, Akamine N, Fischer CH. Echocardiography for hemodynamic evaluation in the intensive care unit. Shock 2010;34(1):59-62.

14. Joseph MX, Disney PJ, Da Costa R, Hutchinson SJ. Transthoracic echocardiography to identify or exclude cardiac cause of shock. Chest 2004;126:1592-1597.

15. Cowie B. Three years' experience of focused cardiovascular ultrasound in the perioperative period. Anaesthesia 2011;66(4): 268-273.

16. Cowie B. Focused cardiovascular ultrasound performed by anesthesiologists in the perioperative period: feasible and alters patient management. J Cardiothorac Vasc Anesth 2009;23:450456.

17. Canty DJ, Royse CF. Audit of anaesthetist-performed echocardiography on perioperative management decisions for noncardiac surgery. Br J Anaesth 2009;103(3):352-358.

18. Canty DJ, Royse CF, Kilpatrich D, Bowman L, Royse AG. The impact of focused transthoracic echocardiography in the preoperative clinic. Anaesthesia 2012; 67(6):618-625.
19. Cowie B. Focused transthoracic echocardiography predicts perioperative cardiovascular morbidity. J Cardiothorasc Vasc Anesth 2012;26(6):989-993.

20. Kimura BJ, Demaria AN. Indications for limited echocardiographic imaging: a mathematical model. J Am Soc Echocardiogr 2000;13:855-861.

21. Holm JH, Frederiksen CA, Juhl-Olsen P, Sloth E. Perioperative use of focus assessed transthoracic echocardiography (FATE). Anesthesia \& Analgesia 2012;115(5):1029-1032.

22. Peng YG, Janelle GM. Emergent limited perioperative transesophageal echocardiography: should new guidelines exist for limited echocardiography training for anesthesiologists? Front Med 2012; 6(3):332-337.

23. Hellman DB, Whiting-O'Keefe Q, Shapiro EP, Martin LD, Martire C, Ziegelstein RC. The rate at which residents learn to use hand-held echocardiography at the bedside. Am J Med 2005;118:1010-1018.

24. Vignon P, Dugard A, Abraham J, Belcour D, Gondran G, Pepino F, Marin B, François B, Gastinne H. Focused training for goal-oriented hand-held echocardiography performed by noncardiologist residents in the intensive care unit. Intensive Care Med 2007;33(10):1795-1799.

25. Vignon P, Mücke F, Bellec F, Marin B, Croce J, Brouqui T, Palobart C, Senges P, Truffy C, Wachmann A, Dugard A, Amiel JB. Basic critical care echocardiography: validation of a curriculum dedicated to noncardiologist residents. Crit Care Med 2011;39(4):636-642.

26. Chalumeau-Lemoine L, Baudel JL, Das V, Arrivé L, Noblinski B, Guidet B, Offenstadt G, Maury E. Results of short-term training of naïve physicians in focused general ultrasonography in an intensive-care unit. Intensive Care Med 2009;35(10):1767-1771.

27. Faris JG, Veltman MG, Royse C. Focused transthoracic echocardiography in the perioperative period. Anaesth Intensive Care 2011;39(2):306-307.

\section{ABOUT THE AUTHORS}

\section{Kelly T Peretich}

Resident, Department of Anesthesiology, University of Pittsburgh Pittsburgh, PA, USA

\section{Jeffrey C Liu}

Clinical Fellow, Department of Cardiology, University of Pittsburgh Pittsburgh, PA, USA

\section{Samir Saba}

Director, Cardiac Electrophysiology Section and Laboratory Cardiovascular Institute, University of Pittsburgh Medical Center (UPMC), Pittsburgh, PA, USA

\section{Heather Byrd}

Faculty, Department of Anesthesiology, UPMC Presbyterian Hospital Pittsburgh, PA, USA

\section{Kathirvel Subramaniam (Corresponding Author)}

Clinical Associate Professor, Department of Anesthesiology, UPMC Presbyterian Hospital, Pittsburgh, PA, USA, e-mail: subramaniamk@ upmc.edu 